\title{
ON THE ECONOMICS OF SOLAR CHEMICAL PROCESSES - CASE STUDY FOR SOLAR CO- PRODUCTION OF METHANOL AND POWER
}

\begin{abstract}
Summary
In several studies, the efficiency of solarized industrial processes was assessed and showed promising results. However, the economic competitiveness of such processes is an unanswered question. In this work, the economic performance of a solar aided methanol production process is determined. The comparative assessment that is carried out yields promising results for the considered co-production process. The presented results also show that for a penetration of renewable energies beyond electricity production, the common support model of fixed feed-in-tariffs is not suitable. A reasonable cost for $\mathrm{CO}_{2}$ emissions or reward for their reduction will allow finding the most economic application for renewable energies independent of the end product of the process.
\end{abstract}

\section{Introduction}

The necessity to reduce greenhouse gas emissions by substituting fossil energy carriers by renewable energy sources such as solar- and wind energy is widely accepted and ongoing today. Regarding the production of electricity, this process has already well advanced in several countries. For instance, in Germany more than $30 \%$ of the electricity was produced from renewable energies in 2015 [1]. However, as also increasingly discussed, the implementation of renewable energies has to advance towards industrial processes to achieve a complete energy transition. von Storch et al. [2] as well as Bai et al. [3] proposed processes for production of methanol with the aid of solar energy that also include further energy streams into and out of the process. In both publications solar energy is used as concentrated solar power (CSP) to provide high temperature heat. Furthermore, both give promising results for the processes regarding the efficiency of solar energy utilization. However, for new renewable energy applications to be commercialized, favorable economics are necessary. Bai et al. [3] give an estimation on economic performance and show methanol prices between 440 and $516 \$ / t$, but they are not put into context with market prices and common costs for renewable energy utilization. In von Storch et al. [2], economic aspects of the proposed process are not assessed at all.

In order to close the gap regarding information on the performance of these processes, the process presented by von Storch et al. [2], which is based on solar aided reforming of natural gas for methanol production (SOLME process), is assessed regarding its economic performance in this work. As can be seen in Figure 1, the process consumes solar energy, natural gas and water to produce electricity and methanol. The production of two products from a renewable and a fossil energy resource complicates the economic assessment. Usually the utilization of renewable energies makes the product more expensive. In the case of facilities for the production of electricity, this is taken care of by increased feed-in-tariffs; which act as subsidy. For methanol production facilities, this procedure is not known. Hence a new approach for economic evaluation is proposed to allow for a fair comparison between different technologies.

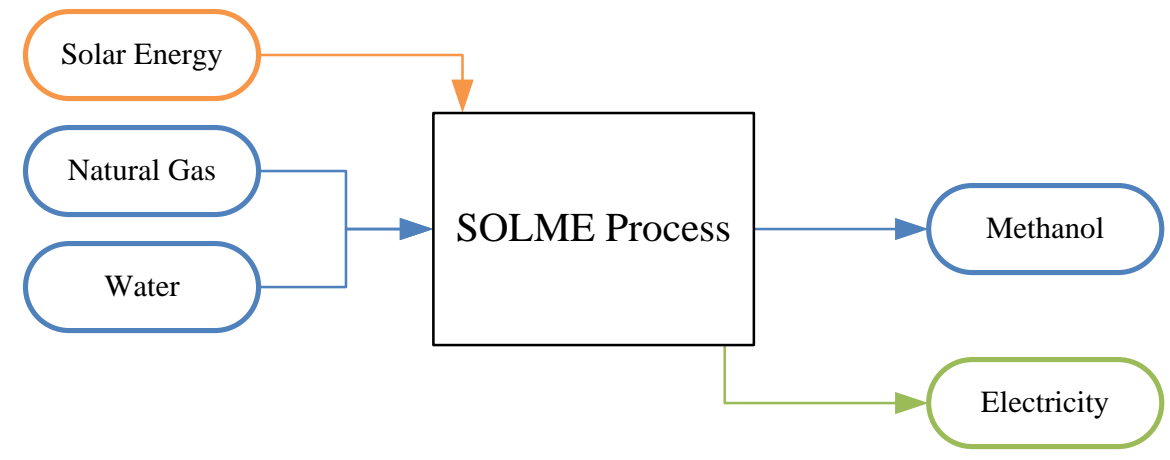

Figure 1 - Schematic of the SOLME process

Regarding the energetic performance of the process, von Storch et al. [2] report that the SOLME process can 
produce a given amount of electricity and methanol from the same amount of solar energy but approx. $5 \%$ less natural gas than a system of conventional methanol synthesis and solar power plant. They state that the plant, that is scaled by the solar receiver with a capacity of $50 \mathrm{MW}$ produces $127.5 \mathrm{GWh}$ of Methanol and $21.41 \mathrm{GWh}$ of electricity per year from 176.1 GWh of solar energy (onto heliostat field) and 148.4 GWh natural gas.

\section{Methodology and procedure}

The central question regarding economics of renewable energy systems that policy makers should ask is: Which renewable energy system achieves a given reduction in $\mathrm{CO}_{2}$ emissions compared to the reference at the lowest cost? This comparison should be possible independent of the product. However, as the example of the recently inaugurated solar power plant crescent dunes shows, besides subsidized loans, solar power plants are mainly supported through an increased feed-in-tariff, in this case 135 \$ $/ \mathrm{MWh}$ [4] (the market price of electricity in that region is approx. $80 \$ / \mathrm{MWh}[5]$ ). In order to address the question, whether the SOLME process or a solar power plant achieves a better economic result, both are assessed without considering the conventional subsidies, but only considering a reward for the reduction of $\mathrm{CO}_{2}$ emissions compared to the fossil reference system (i.e. conventional methanol synthesis and combined cycle gas turbine power plant).

In the assessment of economic performance of renewable energy systems, the levelized cost of electricity (LCOE) is commonly used [6]. In this procedure, the total cost - CAPEX and OPEX - that occur in the process are summed up and divided by the amount of electricity produced to determine the price per unit of electricity (e.g. $\$ / \mathrm{MWh}$ ). However, as the name indicates, the LCOE is used to determine the cost of electricity production. The same procedure can be used to determine for instance the levelized cost of methanol (LCOM), but the concept does not allow determining the production costs of two products. Therefore, in the presented analysis, the price of methanol is set to a fixed value and the resulting LCOE is determined. The fixed methanol price is set to the value that would be realistic for a plant that is solely operated on natural gas. In order to ensure that besides the different means of energy input the same boundary conditions and assumptions are used in determining the cost of methanol from the conventional plant and the SOLME plant, no literature value is used but the price is determined through a separate cost analysis of the conventional plant. The resulting price for methanol is $173.9 \$ / t$, including an interest rate of $8 \%$ on the investment. Hence the revenue from methanol is subtracted from the total cost of the process to determine the price for the electricity.

In the analysis, the SOLME process with the configuration obtained by von Storch et al. [2] is considered. Regarding the solar multiple and thermal energy storage, values of 3.4 and $150 \mathrm{MWh}$ respectively is considered. This yields a capacity factor of $84.5 \%$. In order to be comparable, the solar power plant, with which the economic performance is compared, is a solar power tower designed to achieve the same capacity factor. For the price of natural gas, which is one of the central input parameters, $12 \$ / \mathrm{MWh}$ (current) and $30 \$ / \mathrm{MWh}$ (possible development) are considered. The price of $\mathrm{CO}_{2}$-emissions is varied between 0 and $300 \$ / t_{\mathrm{CO} 2}$.

\section{Results}

The results of the analysis are presented in Figure 2. The LCOEs for the reference solar power plant as well as for the SOLME process in dependence on the price for $\mathrm{CO}_{2}$ emissions are shown. For the SOLME process the result is shown for two different natural gas prices. On the left hand side of the figure, the results for current CSP-component prices are shown. On the right hand side the results for reduced component prices are shown. It can be seen that all LCOEs are reduced with increasing reward for $\mathrm{CO}_{2}$ reduction. It can furthermore be seen, that at no cost for $\mathrm{CO}_{2}$ emissions, the LCOE of the reference solar power plant is lower than for the considered cases of the SOLME process. However, with increasing reward for the reduction of $\mathrm{CO}_{2}$ emissions, there is a break-even point above which the SOLME process achieves a lower LCOE. For current CSP component prices, this point is - depending on natural gas prices - between $100 \$ / t$ and $160 \$ / t$. For reduced CSP component prices, this is between $20 \$ / \mathrm{t}$ and $90 \$ / \mathrm{t}$. A realistic market price for electricity of $80 \$ / \mathrm{MWh}$ is also shown in the figure. It can be seen that the LCOE of SOLME becomes lower than this for cost of $\mathrm{CO}_{2}$ emissions between $80 \$ / t$ (right, red) and $210 \$ / t$ (left, green). The LCOE of the reference solar power plant achieves the value of $80 \$ / M W h$ only with higher rewards for $\mathrm{CO}_{2}$ emissions than the SOLME process. 


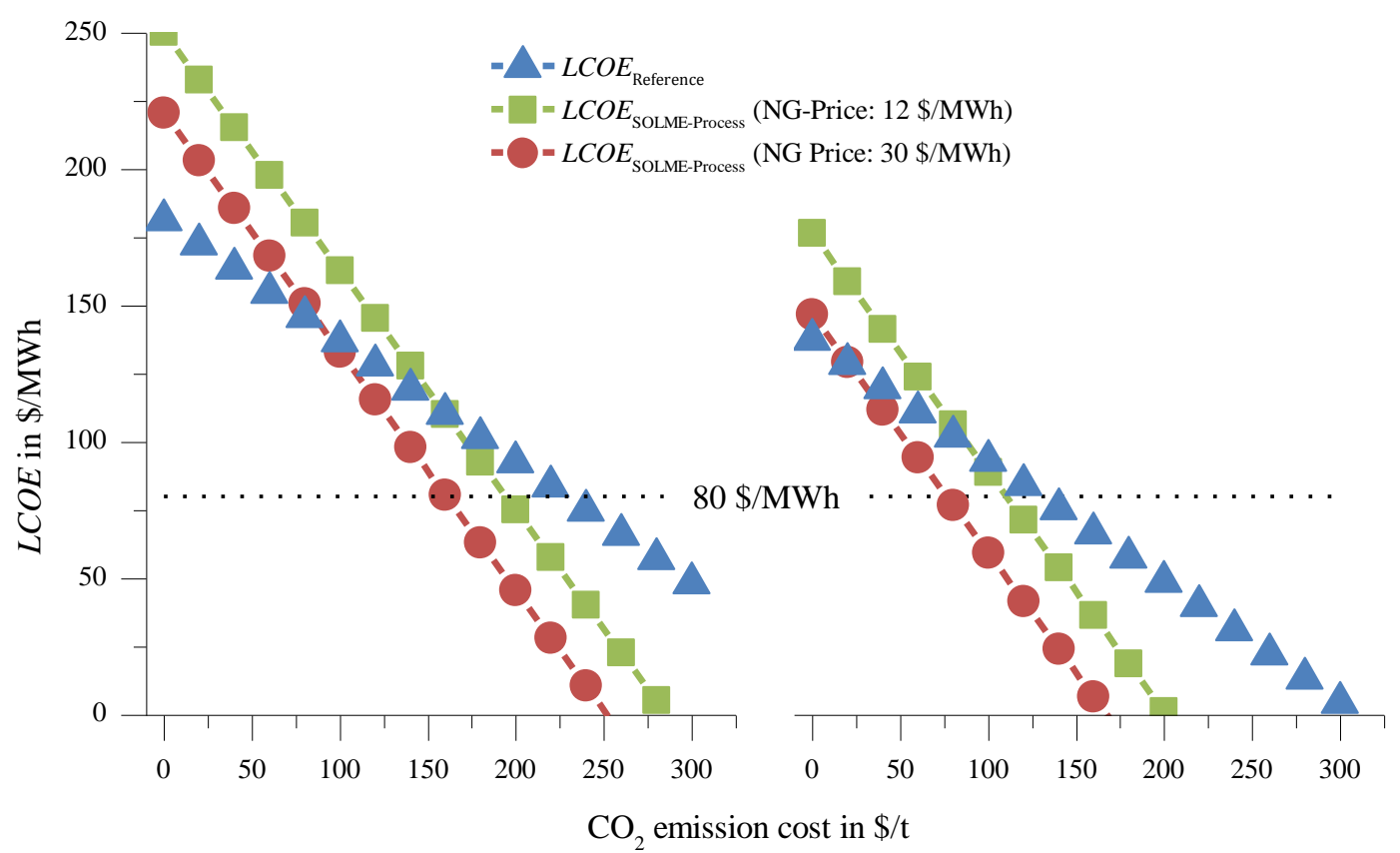

Figure 2 - Results of economic analysis, with current CSP component prices (left) and reduced CSP component prices (right)

\section{Conclusiones}

The comparative analysis of the economic performance of the SOLME process and a conventional solar power plant shows that the result is strongly dependent on the price of $\mathrm{CO}_{2}$ emissions - may it be a reward or penalty. They also show that the result for the LCOE of the SOLME plant strongly depends on the natural gas price, as a high natural gas price will increase revenues for methanol because conventional production of methanol becomes more expensive. For a realistic long term price of $\mathrm{CO}_{2}$ emissions of $100 \$ / t_{\mathrm{CO} 2}$, the SOLME process is expected to achieve a lower LCOE than the conventional solar power plant for most of the considered scenarios. For a very optimistic scenario of high natural gas prices and low CSP component prices the LCOE may even achieve an LCOE below the current market price of $80 \$ / \mathrm{MWh}$. The conventional solar power plant only achieves this value when considering higher costs for $\mathrm{CO}_{2}$ emissions. Hence, the SOLME process shows a very promising economic performance if reasonable costs for $\mathrm{CO}_{2}$ emissions are considered. Therefore, a price for $\mathrm{CO}_{2}$ emissions should be implemented instead of the current feed-in-tariffs for electricity production, to promote the implementation of renewable energies where they are most economical.

\section{References}

1. Renewable Energies in Numbers (in German:Erneuerbare Energien in Zahlen), 2016, Umweltbundesamt (Federal Environmental Agency), URL: www.umweltbundesamt.de/themen/klimaenergie/erneuerbare-energien/erneuerbare-energien-in-zahlen, Accessed: 28.03.2017

2. von Storch, H., Roeb, M., Stadler, H., Sattler, C., Bardow, A., Hoffschmidt, B., On the assessment of renewable industrial processes: Case study for solar co-production of methanol and power, Applied Energy, 183 (2016), 121-132, http://dx.doi.org/10.1016/j.apenergy.2016.08.141

3. Bai, Z., Liu, Q., Lei, J., Li, H., Jin, H., A polygeneration system for the methanol production and the power generation with the solar-biomass thermal gasification, Energy Conversion and Management, (2015), DOI: 10.1016/j.enconman.2015.02.031

4. Parkinson, G., World's biggest solar tower + storage plant to begin generation this month, 14 May 2015, RE new economy, URL: http://reneweconomy.com.au/2015/worlds-biggest-solar-tower-storageplant-to-begin-generation-this-month-22860, Accessed: 14 September 2015

5. $\quad$ Electric Power Monthly - Table 5.6.A. Average Price of Electricity to Ultimate Customers by End-Use Sector, 26 August 2015, U.S. Energy Information and Administration (eia), URL: http://www.eia.gov/electricity/monthly/epm_table_grapher.cfm?t=epmt_5_6_a, $\quad$ Accessed: 14 September 2015

6. Projected Costs of Generating Electricity 2010, International Energy Agency, Nuclear Energy Agency, Organisation for Economic Co-operation and Development, Washington, Palo Alto, 2010, ISBN: 9789264084308. 